\title{
A Compact Rectangular Shaped Dipole Array Slot Microstrip Antenna with DGS for Multiband Applications
}

\author{
Kalavala Vamsi Krishna ${ }^{1}$, Habibulla Khan ${ }^{2}$, Ketavath Kumar Naik $^{3}$ \\ ${ }^{1}$ Dept. of ECE, KLEF, K L Deemed to be University, Vaddeswaram, Guntur, India, vamsikalavala@ gmail.com \\ ${ }^{2}$ Dept. of ECE, KLEF, K L Deemed to be University, Vaddeswaram, Guntur, India, habibulla@kluniversity.in \\ ${ }^{3}$ Dept. of ECE, KLEF, K L Deemed to be University, Vaddeswaram, Guntur, India, kumarnaik@kluniversity.in
}

\begin{abstract}
In this paper, a compact rectangular shaped dipole array slot microstrip antenna for multiband applications with dgs was presented. The proposed microstrip antenna prototype was simulated by using a software Ansys HFSS electromagnetic simulation software. The antenna prototype was designed with dimensions of $42 \times 38 \mathrm{~mm}^{2}$ and resonates at multiple frequencies $5.28 \mathrm{GHz}, 6.24 \mathrm{GHz}, 9.1 \mathrm{GHz}$ and $9.52 \mathrm{GHz}$ respectively. The prototype antenna simulation results exhibit good directional patterns as well as gain plots also with efficient reflection coefficient in addition to current distribution from surface for all multiple resonant frequencies. Reverberations due to changes in dissimilarities with DGS structures has been extensively studied in detail. The proposed microstrip antenna prototype can be used simultaneously at wireless communications and covers the applications under following bands, such as WiMAX, C-band, X-band. Evolution process of proposed prototype antenna is also included.
\end{abstract}

Key words: Dipole array slot, dgs, multiple frequencies, gain, return loss, directional patterns, surface current distribution.

\section{INTRODUCTION}

In present days, wireless communication has become essential part in various communication systems. To obtain long distance data transmission and reception with no physical medium in between, wireless communication is playing vital role over many decades. The advancements happening in today's wireless communication leads to compact, flexible, cost effective and easily fabricated antennas. The C-band is useful for Wi-Fi communication devices, weather radar systems, satellite communication between ground station and satellite. The $\mathrm{X}$-band is useful for weather monitoring, terrestrial microwave links, space communications [1] [2].

To obtain the longer distance communication about over kilometers of range WiMAX technology was discovered to deliver leased broadband digital services for residential customers as well as for enterprise customers with an ease. It would operate at higher speeds with higher bandwidths over greater distances by supporting image and video transmission for huge number of user controls. WiMAX system has the ability to provide internet service for remote area locations and also has ability to overcome challenges compare to wired communication. It has both licensed and unlicensed frequency spectrum. It operates at different frequency bands $(2.4-2.7 \mathrm{GHz}, 3.3-3.8 \mathrm{GHz}$, $5.15-5.85 \mathrm{GHz}$ ) [3] [4]. To satisfy requirements of WiMAX for providing wide coverage major drawback is antenna which is of larger size and cost effective [5] - [7].

Microstrip antennas are basically low profile and high gain antennas designed in order to overcome the drawback with directional radiation pattern and dual band circular polarization therefore different types of basic antenna structures were presented with analysis on gain, return loss, radiation pattern, surface current distribution [8] - [10].

During the beginning days of wireless communication C-band was initially allocated frequency spectrum proposed by federal communications and commission from satellites to via commercial tele-communications. Both the $\mathrm{C}$ and $\mathrm{X}$-band frequency spectrums are used in synthetic aperture radars and moving target indicator radars provide high resolution image of target for identification. A compact microstrip antenna for dual band application prototype was developed with hex-decagon along with dgs, which increases coupling effect between radiating materials [11].

To enhance various parameters like less gain, narrow bandwidth, cross polarization a microstrip antenna design is presented with a pair of concentric ring slots as well as defected ground plane [12] - [14]. In earlier days microstrip antennas primary aim is to reduce cross polarization and majorly focused on single antenna elements. Later on, defected ground structure was considered for antenna array elements to suppress the cross polarization over $10 \mathrm{~dB}-15 \mathrm{~dB}$ majorly in Horizontal Plane, therefore observed the results about more than $25 \mathrm{~dB}$ isolation among co-polarization, cross-polarization in the primary planes as well as suppressing the mutual coupling occurred due to surface waves because of impedance mismatch between transmitter and receiver [15]. 


\section{ANTENNA DESIGN}

\subsection{Microstrip antenna with rectangular dipole array slots and defected ground structure.}

Below, Figure 1 depicts a compact rectangular dipole slot array proposed microstrip antenna with dgs. Below antenna prototype was depicted on FR4 material with dielectric constant and loss tangent as $\left(\varepsilon_{\mathrm{r}}\right) 4.4$, and $(\delta) 0.02$. Now the length $\left(\mathrm{L}_{1}\right)$, width $\left(\mathrm{W}_{1}\right)$ along with height $(\mathrm{h})$ are dimensions of FR4 material. The materials used for antenna prototype were mentioned in Table 1.

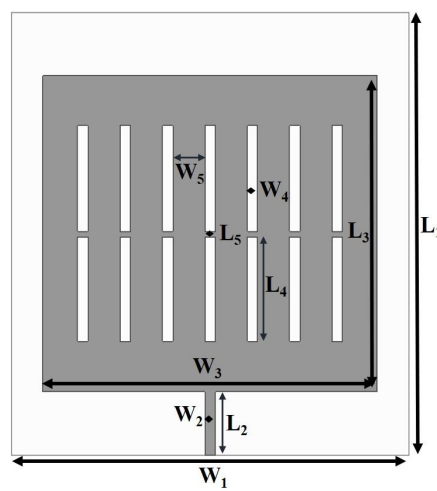

(a)

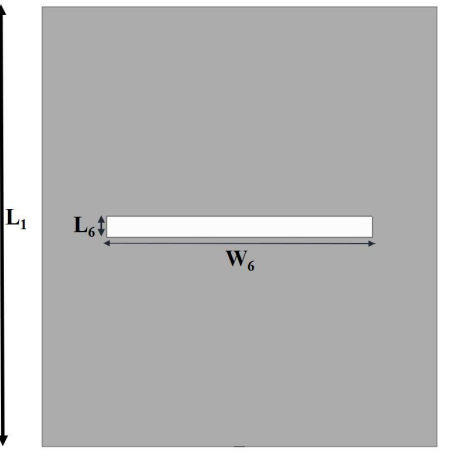

(b)
Figure 1: View of prototype antenna (a) Front, (b) Back.

\subsection{Materials used in proposed antenna prototype.}

Table 1: Materials used

\begin{tabular}{|c|c|c|c|}
\hline S. No. & $\begin{array}{l}\text { Parameter } \\
\text { s }\end{array}$ & Material & Thickness (mm) \\
\hline 1 & Substrate & FR4 Epoxy & 1.59 \\
\hline 2 & Patch & Copper & 0.01 \\
\hline 3 & Ground & Pec & 0.01 \\
\hline
\end{tabular}

A radiating copper material which is in rectangular shape and metalized on the FR4 substrate material with length $\left(\mathrm{L}_{3}\right)$ and width $\left(\mathrm{W}_{3}\right)$ respectively. An array of rectangular dipole slots was etched from the copper material with dimensions' length $\left(\mathrm{L}_{4}\right)$ and width $\left(\mathrm{W}_{4}\right)$ and the gap between each slot is length $\left(\mathrm{L}_{5}\right)$ and width $\left(\mathrm{W}_{5}\right)$ is shown above in Figure 1(a).

A line feeding technique with input impedance $\left(\mathrm{Z}_{\mathrm{i}}\right)$ of $50 \Omega$ is fed through radiating copper material. Dimensions of line feeding is length $\left(\mathrm{L}_{2}\right)$ and width $\left(\mathrm{W}_{2}\right)$ respectively. The pec material from the ground plane is defected by etching pec material with rectangle shaped slot and the dimensions are length $\left(\mathrm{L}_{6}\right)$ and width $\left(\mathrm{W}_{6}\right)$, which is shown above in Figure $1(\mathrm{~b})$, and the dimensions of prototype antenna were mentioned in Table 2.

\subsection{Antenna prototype design equations.}

Width of patch: $W=\frac{C_{o}}{2 f_{r}} \sqrt{\frac{2}{\varepsilon_{r}+1}}$
Length of patch: $L=\frac{C_{o}}{2 f_{r} \sqrt{\varepsilon_{r}+\varepsilon_{\text {air }}}}-2 \Delta L$

(2)

Effective length: $\mathrm{L}_{\text {eff }}=\mathrm{L}+2 \Delta \mathrm{L}$

Height of substrate: $\mathrm{h} \leq 0.05 \lambda_{\text {。 }}$

Effective length of patch: $L_{\text {eff }}=\frac{C_{o}}{2 f_{r} \sqrt{\varepsilon_{r}+\varepsilon_{\text {air }}}}$

Frequency of operation: $f_{r}=\frac{C_{o}}{2 L_{\text {eff }} \sqrt{\varepsilon_{r}}}$

Effective dielectric: $\varepsilon_{\text {reff }}=\frac{\varepsilon_{\mathrm{r}}+1}{2}+\frac{\varepsilon_{\mathrm{r}}-1}{2}\left[1+12 \frac{\mathrm{h}}{\mathrm{w}}\right]^{-1 / 2}$

Change in patch length: $\Delta \mathrm{L}=0.412 \mathrm{~h} \frac{\left(\varepsilon_{\text {erff }}+0.3\right)\left(\frac{\mathrm{w}}{\mathrm{h}}+0.264\right)}{\left(\varepsilon_{\text {reff }}-0.258\right)\left(\frac{\mathrm{w}}{\mathrm{h}}+0.8\right)}$

2.4 Dimensions of microstrip antenna prototype.

Table 2: Optimum parameters

\begin{tabular}{|c|c|c|c|}
\hline Parameter & $\begin{array}{c}\text { Optimum } \\
\text { value (mm) }\end{array}$ & Parameter & $\begin{array}{c}\text { Optimum } \\
\text { value (mm) }\end{array}$ \\
\hline $\mathrm{L}_{1}$ & 42 & $\mathrm{~W}_{1}$ & 38 \\
\hline $\mathrm{L}_{2}$ & 6 & $\mathrm{~W}_{2}$ & 1 \\
\hline $\mathrm{L}_{3}$ & 30 & $\mathrm{~W}_{3}$ & 32 \\
\hline $\mathrm{L}_{4}$ & 10 & $\mathrm{~W}_{4}$ & 1 \\
\hline $\mathrm{L}_{5}$ & 0.5 & $\mathrm{~W}_{5}$ & 3.065 \\
\hline $\mathrm{L}_{6}$ & 2 & $\mathrm{~W}_{6}$ & 25.6 \\
\hline
\end{tabular}

\section{RESULTS OF MICROSTRIP ANTENNA}

\subsection{Reflection coefficient (dB) of antenna prototype.}

The rectangular shaped dipole array slot microstrip antenna prototype analysis has been carried out by using HFSS 19.0 simulator software and the antenna was resonating at multiple frequencies, for $5.28 \mathrm{GHz}$, reflection coefficient is $-27.87 \mathrm{~dB}$ and impedance bandwidth is $140 \mathrm{MHz}$. For $6.24 \mathrm{GHz}$, reflection coefficient is $-17.20 \mathrm{~dB}$ and impedance bandwidth is $120 \mathrm{MHz}$. For $9.1 \mathrm{GHz}$, reflection coefficient is $-26.4 \mathrm{~dB}$ and impedance bandwidth is $1.16 \mathrm{GHz}$. For $9.52 \mathrm{GHz}$, reflection coefficient is $-31.7 \mathrm{~dB}$ and impedance bandwidth is $1.16 \mathrm{GHz}$ respectively, Figure 2 depicts reflection coefficient for prototype microstrip antenna suitable in WiMAX. C-band and X-band applications. 


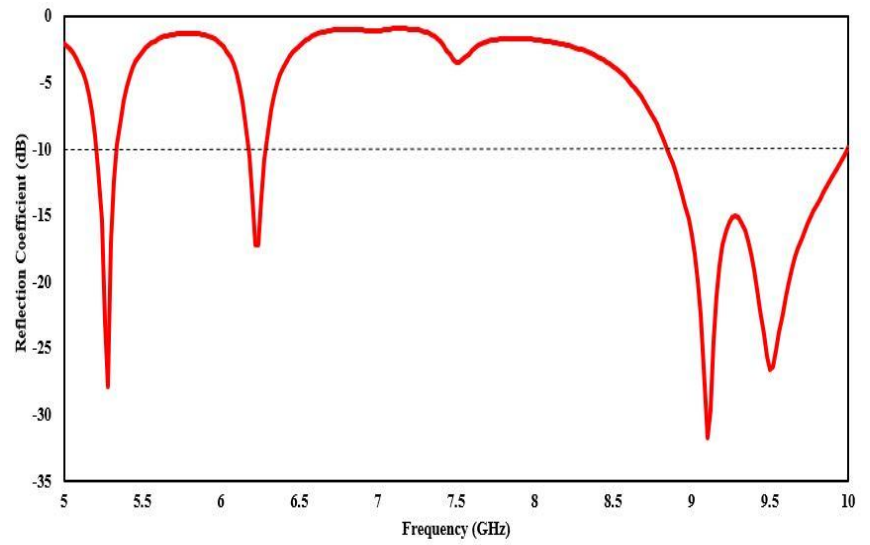

Figure 2: Reflection coefficient $(\mathrm{dB})$ for microstrip antenna.

\subsection{Evolution process of microstrip antenna prototype.}

Below, Figure 3 depicts step-by-step process of rectangular shaped array slot microstrip antenna prototype.

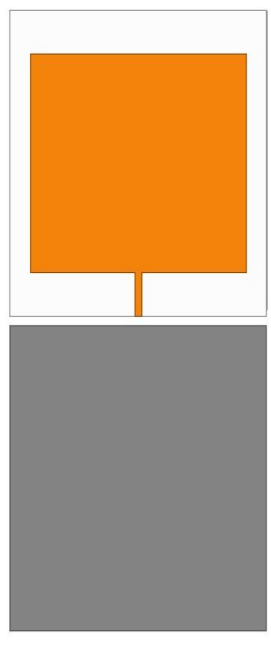

(a) Antenna 1

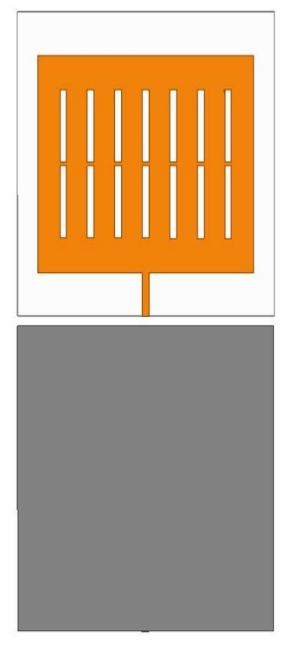

(b) Antenna 2

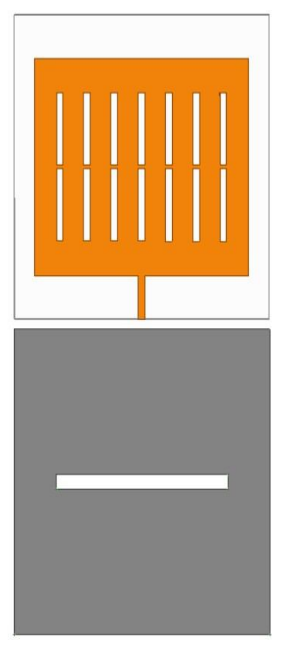

(c) Antenna 3
Figure 3: Antenna evolution process (a) Rectangular patch with full ground (b) Rectangular array slots on patch with full ground (c) Defected structure in ground plane.

\subsection{Reflection coefficients for rectangular array slot} microstrip antenna prototype evolution process.

Below, Figure 4 depicts the rectangular shaped array slot microstrip antenna reflection coefficients $(\mathrm{dB})$. In the first step, a rectangular microstrip antenna with full ground is considered as shown in Antenna 1 and shows resonance at both C-band, $\mathrm{X}$-band frequency range.

The Antenna 2 is designed by placing dipole array slots by etching copper material on patch from Antenna 1 and shows resonance at $\mathrm{S}$-band, $\mathrm{C}$ and $\mathrm{X}$-band frequency range. Hence, we require the proposed antenna to work in WiMAX frequency range therefore defected ground structure is implemented.

To obtain shift in the frequency when copper material from the ground plane is etched due to coupling effect between patch and ground leads to increase in effective capacitance and inductance as shown in Antenna 3. Therefore, we obtained resonance at WIMAX, C-band and X-band microwave frequency ranges as mentioned in Table 3 for further reference.

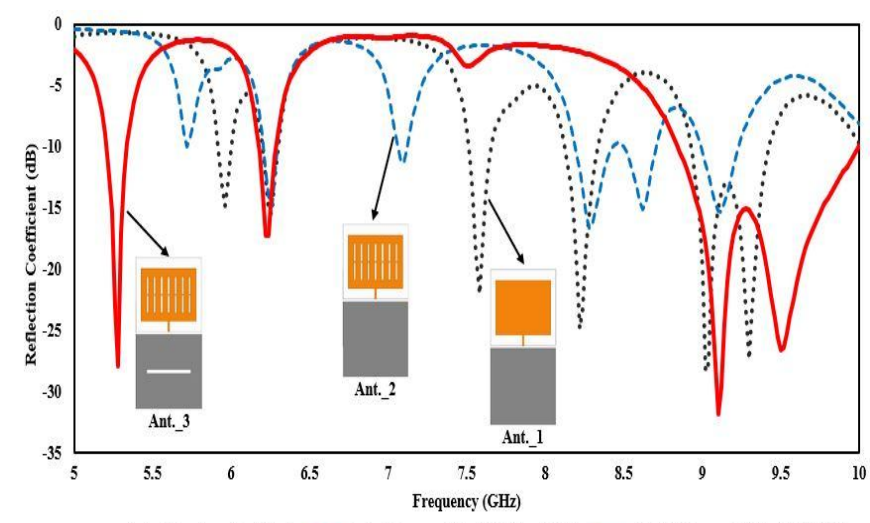

.....Ant._1 Rectangular Patch =- Ant. 2 Array of Slots Without DGS -Ant._3 Array of Slots With DGS

Figure 4: Reflection coefficient for evolution process of antenna.

\subsection{Evolution process results of proposed antenna.}

Table 3: Evolution process results

\begin{tabular}{|c|c|c|c|c|}
\hline $\begin{array}{l}\text { S. } \\
\text { No. }\end{array}$ & $\begin{array}{c}\text { Evolution } \\
\text { Antenna }\end{array}$ & $\begin{array}{c}\text { Resonant } \\
\text { Frequency } \\
\text { (GHz) }\end{array}$ & $\begin{array}{c}\text { Reflection } \\
\text { coefficien } \\
\mathbf{t}(\mathbf{d B})\end{array}$ & $\begin{array}{c}\text { Bandwidt } \\
\text { h (MHz) }\end{array}$ \\
\hline \multirow{6}{*}{1} & \multirow{6}{*}{ Antenna 1} & 5.96 & -14.86 & 80 \\
\hline & & 6.26 & -15.51 & 100 \\
\hline & & 7.58 & -22.06 & 140 \\
\hline & & 8.22 & -24.8 & 220 \\
\hline & & 9.02 & -28.34 & 480 \\
\hline & & 9.3 & -27.34 & 480 \\
\hline \multirow{7}{*}{2} & \multirow{7}{*}{ Antenna 2} & 2.31 & -30.30 & 100 \\
\hline & & 4.64 & -16.15 & 90 \\
\hline & & 6.73 & -14.73 & 120 \\
\hline & & 7.66 & -11.34 & 110 \\
\hline & & 8.97 & -15.63 & 290 \\
\hline & & 9.35 & -15.13 & 220 \\
\hline & & 9.91 & -15.31 & 290 \\
\hline \multirow{4}{*}{3} & \multirow{4}{*}{ Antenna 3} & 5.28 & -27.87 & 140 \\
\hline & & 6.24 & -17.19 & 120 \\
\hline & & 9.1 & -31.76 & 1160 \\
\hline & & 9.52 & -26.37 & 1160 \\
\hline
\end{tabular}

3.5 3D-Gain plots of rectangular array slot microstrip antenna prototype.

Below, Figure 5 shows 3D Gain plots for microstrip antenna prototype and maximum gain was observed at $9.1 \mathrm{GHz}$ frequency with $7.21 \mathrm{~dB}$. 

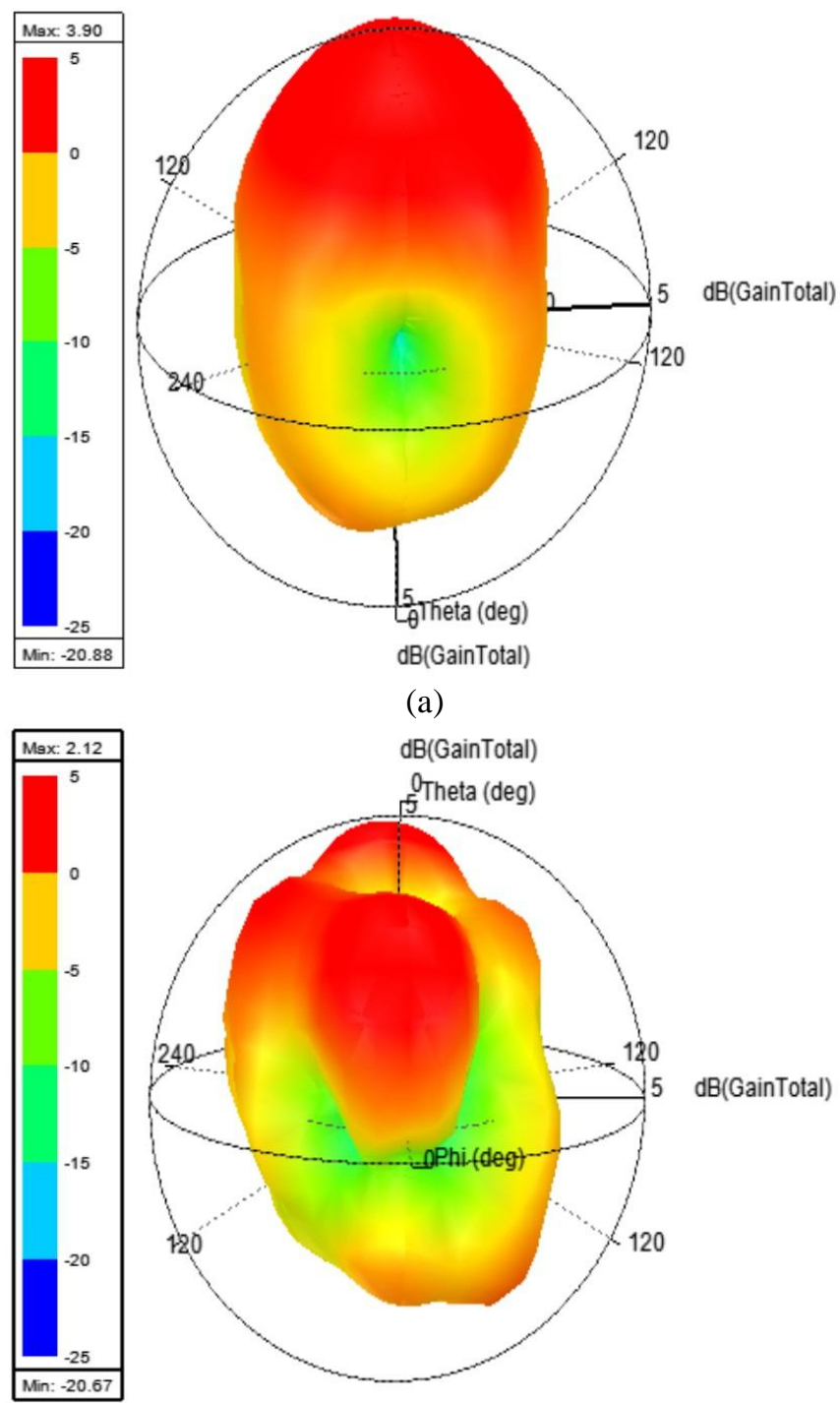

(a)

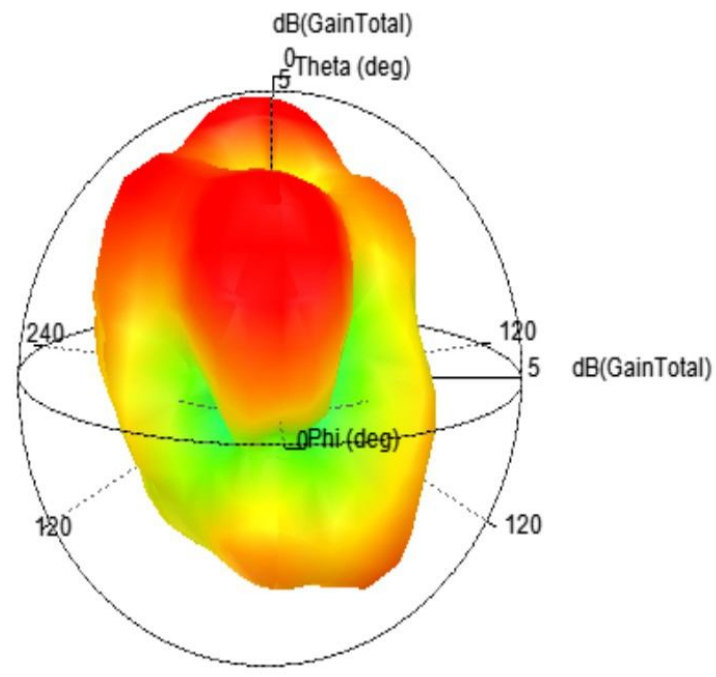

(b)

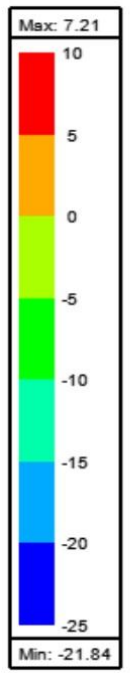

$\mathrm{dB}$ (GainTotal)

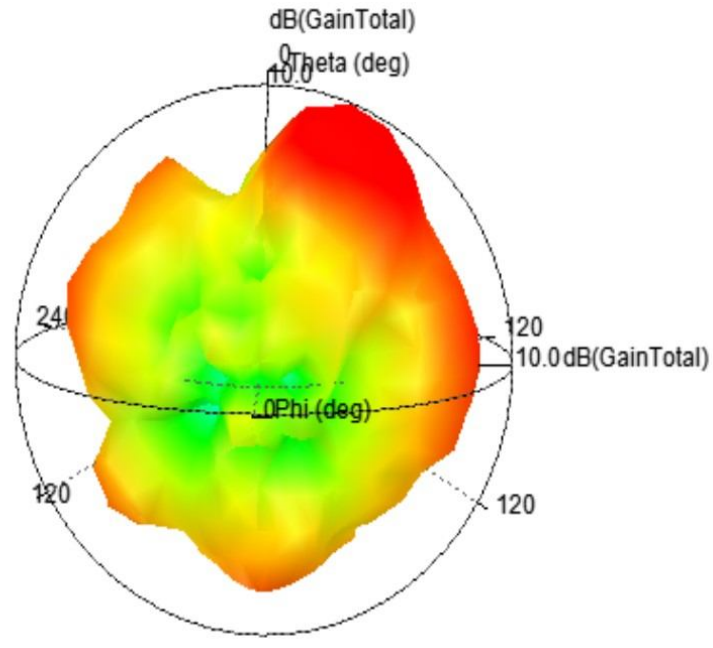

(c)
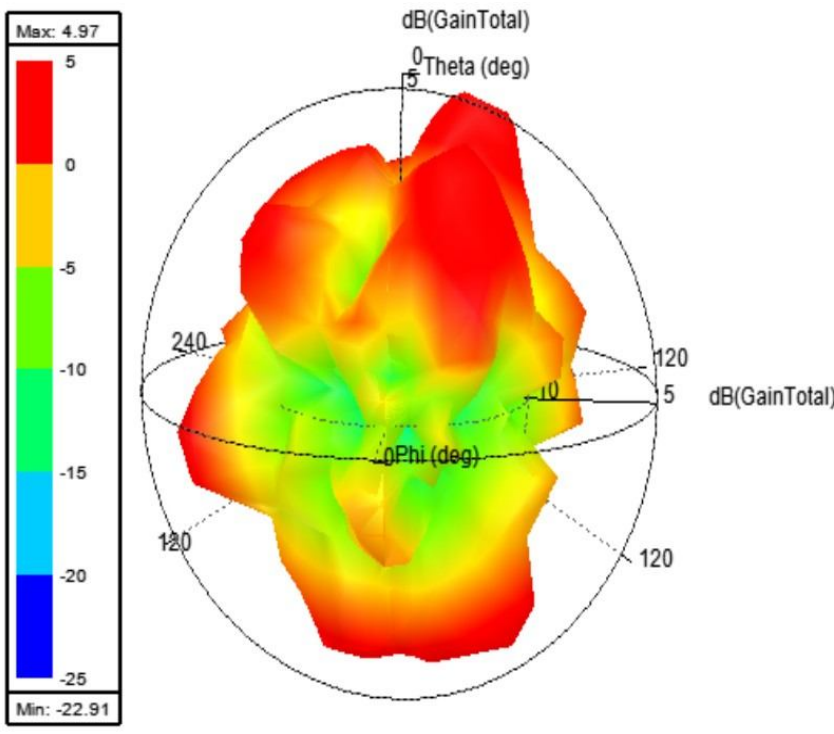

(d)

Figure 5: 3D Gain plots for rectangular array slot microstrip antenna (a) $5.28 \mathrm{GHz}$ (b) $6.24 \mathrm{GHz}$ (c) $9.1 \mathrm{GHz}$ (d) $9.52 \mathrm{GHz}$.

\subsection{Radiation pattern for rectangular array slot microstrip antenna prototype.}

Below, Figure 6 depict antenna direction of radiation plots. Directional pattern contains radiation properties with respect to spatial coordinates. It includes intensity of radiation, strength of electric field or magnetic field, directivity of antenna, polarization properties of antenna. In Table 4 below E-plane represents Phi $=0^{\circ}$ and $\mathrm{H}$-plane represents $\mathrm{Phi}=90^{\circ}$ for multiple resonant frequencies. The radiation pattern plots are presented for multiple resonant frequencies $5.28 \mathrm{GHz}$, $6.24 \mathrm{GHz}, 9.1 \mathrm{GHz}$ and $9.52 \mathrm{GHz}$ respectively.

Table 4: Radiation pattern at multiple frequencies.

\begin{tabular}{|c|c|c|c|}
\hline Label & Frequency (GHz) & E-Plane & H-Plane \\
\hline a & 5.28 & $181^{0}$ & $179^{0}$ \\
\hline b & 6.24 & $325^{0}$ & $324^{0}$ \\
\hline c & 9.1 & $162^{0}$ & $23^{0}$ \\
\hline d & 9.52 & $320^{0}$ & $152^{0}$ \\
\hline \multicolumn{4}{|c}{-E-Plane - - - H-Plane } \\
\end{tabular}

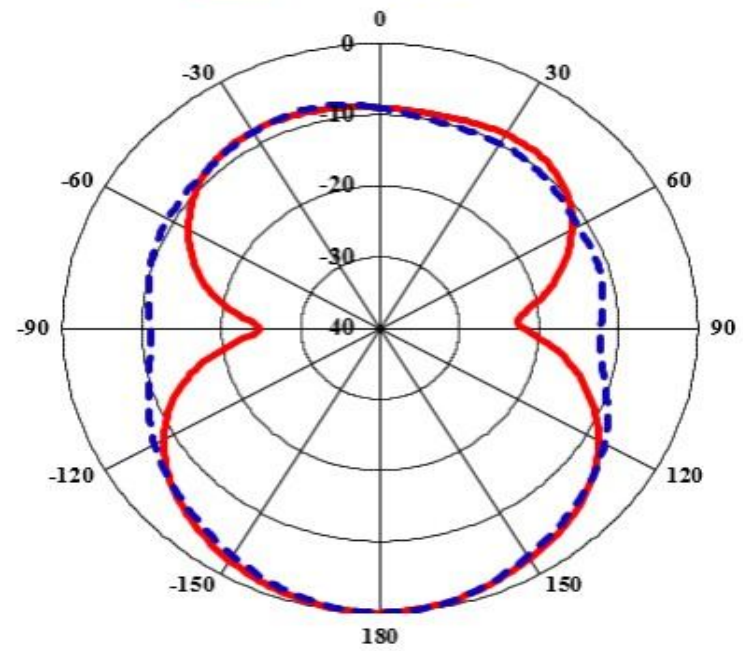

(a) 


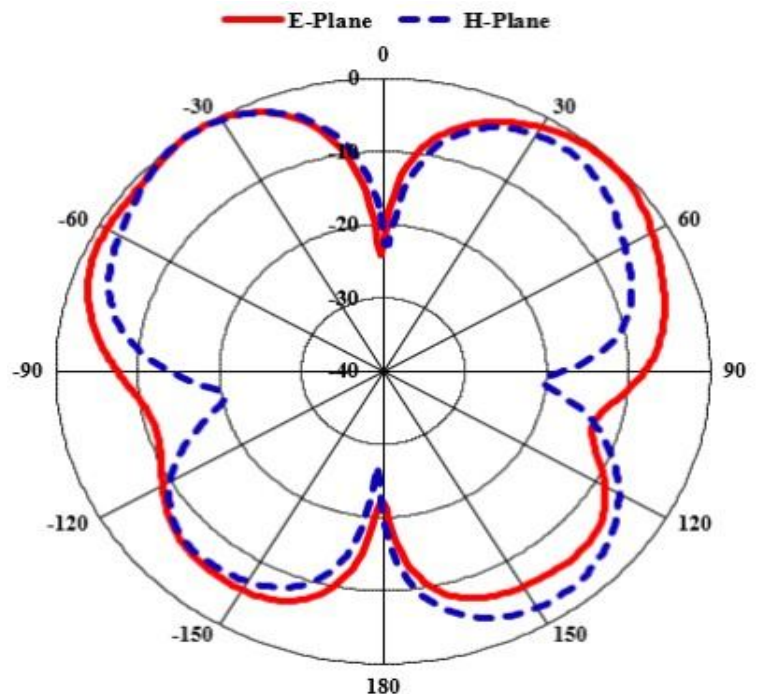

(b)

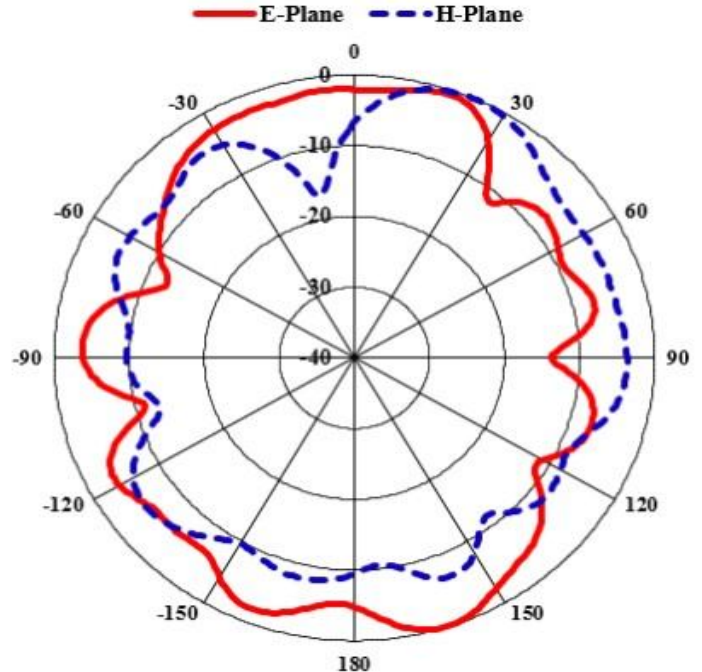

(c)

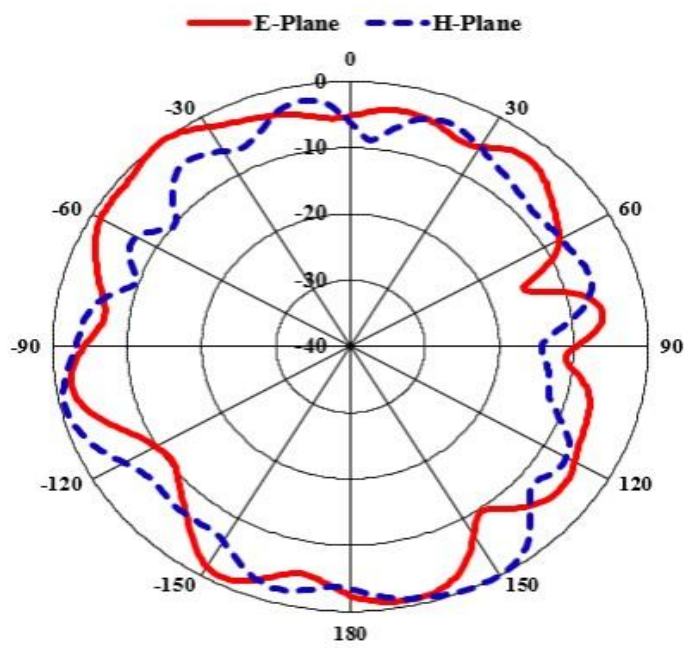

(d)

Figure 6: Radiation patterns for rectangular array slot microstrip antenna (a) $5.28 \mathrm{GHz}$ (b) $6.24 \mathrm{GHz}$ (c) $9.1 \mathrm{GHz}$ (d) $9.52 \mathrm{GHz}$.

\subsection{Surface current distribution for rectangular array slot microstrip antenna.}

Below, Figure 7 shows current distribution for microstrip antenna prototype at frequencies $5.28 \mathrm{GHz}, 6.24 \mathrm{GHz}, 9.1 \mathrm{GHz}$ and $9.52 \mathrm{GHz}$ respectively. The figures below show the current density and flow of $\mathrm{e}^{-}$field movement inside the proposed antenna prototype along with density meter for multiple frequencies.

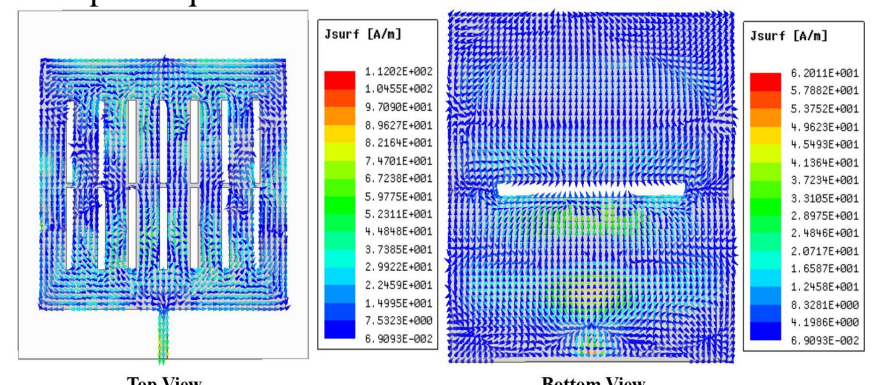

(a)

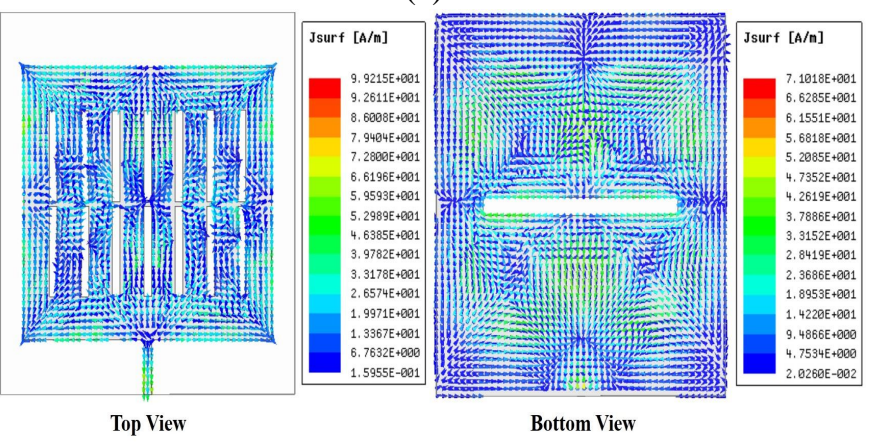

(b)

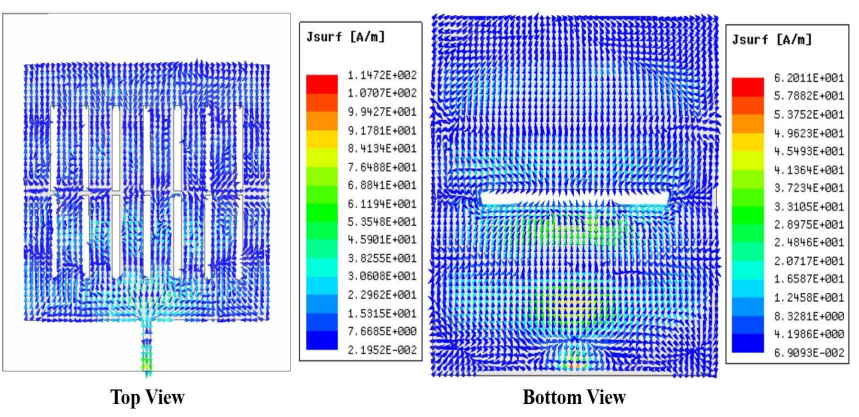

(c)

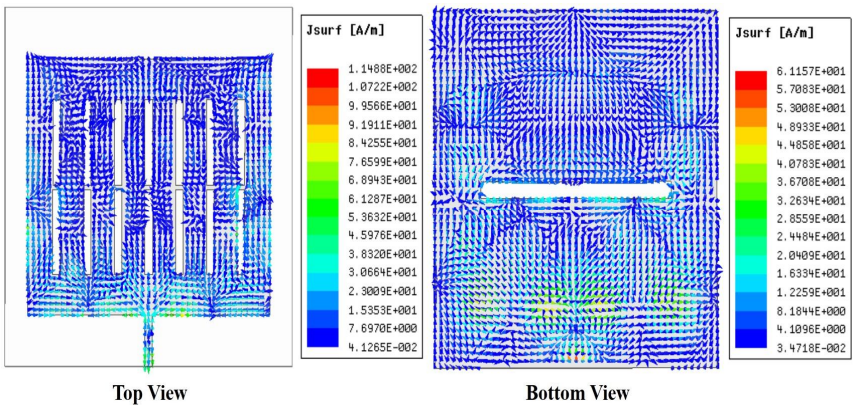

(d)

Figure 7: Surface current distribution for rectangular array slot microstrip antenna (a) $5.28 \mathrm{GHz}$ (b) $6.24 \mathrm{GHz}$ (c) $9.1 \mathrm{GHz}$ (d) $9.52 \mathrm{GHz}$. 


\section{CONCLUSION}

A compact multiband rectangle shaped array slot antenna with defected ground structure prototype has been carried out by Ansys HFSS_19.0 simulator software with a total size of $38 \times 42 \times 1.59 \mathrm{~mm}^{3}$. Now, prototype of microstrip antenna resonates at multiple resonant frequencies that are $5.28 \mathrm{GHz}$, $6.24 \mathrm{GHz}, 9.1 \mathrm{GHz}$ and $9.52 \mathrm{GHz}$ with an impedance bandwidth of $140 \mathrm{MHz}, 120 \mathrm{MHz}, 1.16 \mathrm{GHz}$ respectively. The proposed microstrip patch antenna prototype covers following communication bands that are WiMAX, C and X-band. The applications are radio location, fixed satellite, aeronautical radio navigation, terrestrial broadband. Evolution process analysis is also included to give an epitome of proposed microstrip antenna prototype performance.

\section{REFERENCES}

1. Balanis C.A., Antenna Theory, Analysis and Design, (John Wiley, New York), 1982.

2. J. M. Fernandez Gonzalez, P. Padilla, G. Exposito Dominguez, and M. Sierra-Castaner, Lightweight Portable Planar Slot Array Antenna for Satellite Communications in X-Band, IEEE Antennas and Wireless Propagation Letters, vol. 10, pp. 1409 - 1412, Dec. 2011. https://doi.org/10.1109/LAWP.2011.2178584

3. Hsien-Wen Liu, Chia-Hao $\mathrm{Ku}$, and Chang-Fa Yang, Novel CPW-Fed Planar Monopole Antenna for WiMAX/WLAN Applications, IEEE Antennas and Wireless Propagation Letters, vol. 9, pp. 240 - 243, Mar. 2010.

4. Li Li, Xiaoliang Zhang, Xiaoli Yin, Le Zhou, A Compact Triple-Band Printed Monopole Antenna for WLAN/WiMAX Applications, IEEE Antennas and Wireless Propagation Letters, vol. 15, pp. 1853 - 1855, Mar. 2016.

5. Debdeep Sarkar, Kumar Vaibhav Srivastava, Kushmanda Saurav, A Compact Microstrip-Fed Triple Band-Notched UWB Monopole Antenna, IEEE Antennas and Wireless Propagation Letters, vol. 13, pp. 396 - 399, Feb. 2014. https://doi.org/10.1109/LAWP.2014.2306812

6. W. X. Liu, Y. Z. Yin, W. L. Xu, Compact Self-Similar Triple-Band Antenna for WLAN/WiMAX Applications, Microwave and Optical Technology Letters, vol. 54, no. 4, pp. 1084 - 1087, Apr. 2012.

7. Xin Li, Wei Hu, Ya Fang Wang, Xiao Wei Shi, Xin Tao $\mathrm{Gu}$, Printed Triple-Band Rectangular Ring Monopole Antenna With Symmetrical L-Strips for WLAN/WiMAX Applications, Microwave and Optical Technology Letters, vol. 54, no. 4, pp. 1049 - 1052, Feb. 2012.

8. N. Siddaiah, B. Sri Keerthana Reddy, B. Manoj Kumar, K. Raja Sekhar, G. Venkata Ganesh, Performance Analysis Of Low Pullin Voltage RF MEMS Switch for Reconfigurable Antenna Applications, International
Journal of Emerging Trends in Engineering Research, Vol. 7, pp. 670 - 676, Nov. 2019. https://doi.org/10.30534/ijeter/2019/427112019

9. A. Bendali, S. Bri, M. Habibi, M. N. Srifi, A. El fellahin, Study and Design a Novel Adaptive Array Antenna for a RFID Applications, International Journal of Emerging Trends in Engineering Research, Vol. 8, pp. 805 - 811, Dec. 2019.

10. Y. Liu, Z. Shen, C. L. Law, A Compact Dual-band Cavity-backed Slot Antenna, IEEE Antennas and Wireless Propagation Letters, vol. 5, pp. 4 - 6, Mar. 2006.

11. Yijun Liu, Zhongxiang Shen, A Compact Dual and Wideband Cavity-Backed Slot Subarray, IEEE Antennas and Wireless Propagation Letters, vol. 6, pp. 80 - 82, Mar. 2007.

12. Ketavath Kumar Naik, Pasumarthi Amala Vijaya Sri, Design of Hexadecagon Circular Patch Antenna with DGS at Ku band for Satellite communications, Progress In Electromagnetics Research M, vol. 63, pp. 163 - 173, Jan. 2018. https://doi.org/10.2528/PIERM17092205

13. Ketavath Kumar Naik, Pasumarthi Amala Vijaya Sri, Design of Concentric Ring Patch with DGS for Dual-Band at Satellite Communication and Radar Applications, Wireless Personal Communications, vol. 98, pp. 2993 - 3001, Nov. 2017.

14. D. Guha, M. Biswas, Y. M. M. Antar, Microstrip Patch Antenna With Defected Ground Structure for Cross Polarization Suppression, IEEE Antennas and Wireless Propagation Letters, vol. 4, pp. 455 - 458, Dec. 2005.

15. Mohsen Salehi, Ahad Tavakoli, A Novel Low Mutual Coupling Microstrip Antenna Array Design Using Defected Ground Structure, AEU - International Journal of Electronics and Communications, vol. 60, pp. 718 - 723, Nov. 2006. https://doi.org/10.1016/j.aeue.2005.12.009 